\title{
A Clinical Study to Assess the Efficacy of Erector Spinae Plane Block for Postoperative Analgesia after Modified Radical Mastectomy in a Tertiary Health Care Centre
}

\author{
Deepa George ${ }^{1}$, Nanna Ramachandran ${ }^{2}$ \\ ${ }^{1,2}$ Department of Anaesthesiology, Government T D Medical College, Alappuzha, Kerala, India.
}

\section{ABSTRACT}

\section{BACKGROUND}

Interfascial blocks like erector spinae plane block (ESP block) are relatively easy to perform and have potentially low risk profile. This study wanted to assess the efficacy of ultrasound guided ESP block for postoperative analgesia after modified radical mastectomy (MRM) as compared to conventional technique of surgical wound infiltration with local anaesthetic. The primary objective of the study was to assess the duration of postoperative analgesia.

\section{METHODS}

After obtaining institutional ethics committee clearance, a total of 26 females posted for MRM were randomly allocated into Group A (control group) and Group B (block group). Patients in Group A received general anaesthesia and local infiltration with $20 \mathrm{ml}$ of $0.25 \%$ bupivacaine towards the end of surgery whereas patients in Group B received ultrasound guided ESP block preoperatively with $10 \mathrm{ml}$ of $2 \%$ lignocaine with adrenaline and $20 \mathrm{ml}$ of $0.25 \%$ bupivacaine with $8 \mathrm{mg}$ dexamethasone followed by general anaesthesia. Difference between the two groups were analysed using Mann Whitney U test or independent $t$ test.

\section{RESULTS}

Duration of postoperative analgesia was significantly prolonged in ESP block group $(2594.62 \pm 216.742 \mathrm{~min}$ in block group vs. $274.2 \pm 33.3 \mathrm{~min}$ in control group). Rest and motion VAS scores were significantly lower in ESP block group compared to control group. Also, patient satisfaction score in ESP block group was higher than in control group. Perioperative requirement of opioids and NSAIDs were significantly lower in ESP block group compared to control group.

\section{CONCLUSIONS}

ESP block is an effective block for prolonged postoperative analgesia after MRM.

\section{KEY WORDS}

Postoperative Analgesia, Modified Radical Mastectomy, Erector Spinae Plane Block
Corresponding Author: Dr. Nanna Ramachandran, Assistant Professor Department of Anaesthesiology, Government T D Medical College, Alappuzha-688005., Kerala, India E-mail: nannapratap@yahoo.com

DOI: $10.14260 /$ jemds/2022/73

How to Cite This Article: George D, Ramachandran N. A clinical study to assess the efficacy of erector spinae plane block for postoperative analgesia after modified radical mastectomy in a tertiary health care centre. J Evolution Med Dent Sci 2022;11(02):380-385, $10.14260 / \mathrm{jemds} / 2022 / 73$

Submission 09-11-2021, Peer Review 21-11-2021, Acceptance 04-02-2022, Published 07-02-2022.

Copyright (C) 2022 Deepa George et al. This is an open access article distributed under Creative Commons Attribution License [Attribution 4.0 International (CC BY 4.0)] 


\section{BACKGROUND}

Among Indian females, breast cancer has ranked number one, with age adjusted rate of 25.8 per 100,000 women and mortality of 12.7 per 100,000 women. ${ }^{1}$ Modified radical mastectomy (MRM) is the most common surgical treatment done for breast cancer and it is very painful postoperatively. In our hospital MRM is done under general anaesthesia and local infiltration with bupivacaine is given towards completion of the procedure. It has been shown that local infiltration with bupivacaine and ropivacaine during breast surgery decreased pain significantly at 2 hours, but there was no reduction of pain at 12 and 24 hours in the postoperative period. ${ }^{2}$

So newer modalities of pain relief like interfascial blocks have been introduced. For mastectomies an erector spinae plane block (ESP block) is used wherein drug is deposited into the fascial plane deep to erector spinae muscle where it diffuses anteriorly via costo transverse foramina into the vicinity of origin of dorsal and ventral rami of thoracic spinal nerve which is the likely site of action as indicated by anatomical and radiological studies in fresh cadaver. ${ }^{3}$

Erector spinae block is effective, relatively easy to perform and has been successfully used for providing postoperative analgesia after bariatric surgery, video assisted thoracoscopic surgery and laparoscopic cholecystectomy. ${ }^{4,5,6}$ As the block is given peripherally, not much of sympathetic blockade is expected and risk of bleeding is less as there are no major blood vessels in the vicinity. The transverse process acts as a definite sonographic landmark and prevents further advancement of needle. This contributes to the safety and ease of block. Therefore, this block may be safe for both awake and anaesthetised patients.

The purpose of the study was to assess the efficacy of ultrasound guided ESP block to prolong the duration of postoperative analgesia following MRM as compared to the conventional technique of surgical wound infiltration with local anaesthetic.

\section{Objectives of the Study}

\section{Primary Objective}

To determine the duration of analgesia based on the time needed for first dose rescue analgesia in patients undergoing modified radical mastectomy and getting subcutaneous infiltration verses erector spinae plane block.

\section{Secondary Objective}

Compare the total dose of fentanyl and vecuronium needed in intraoperative period, total dose of tramadol and paracetamol needed at 24, 48 hours postoperatively, quality of analgesia based on VAS at rest and at arm abduction at $1,2,4,6,12,18,24,30,36,42,48$ hours postoperatively, incidence of side effects like back ache and failure of block or sparing of dermatomes, incidence of opioid related side effects.

\section{METHODS}

This randomised prospective study was conducted in 26 informed and consented female patients from September 2019 to August 2020 in a tertiary health care centre. The study was approved by Institutional Ethics Committee (EC 42/2019) and registered prospectively in the Clinical Trial Registry, India with identification number (CTRI/2019/08/020897).

\section{Inclusion Criteria}

1. Women in the age group of 25-70 years scheduled to undergo MRM for breast carcinoma.

2. ASA 1-4 patients.

\section{Exclusion Criteria}

1. History or current clinically significant medical disease or condition.

2. History of allergy to local anaesthetics.

3. Refusal of patient to participate in study.

4. Psychiatric patients.

5. $B M I>40$.

6. Patients with pre-existing coagulation abnormalities.

Preanesthetic check-up was done in all patients on the day prior to surgery and they were introduced to the concept of VAS. Informed written consent was obtained in local language. They were kept nil per oral 8 hours before surgery and were given oral ranitidine $150 \mathrm{mg}$ and metoclopramide $10 \mathrm{mg}$ at night on the previous day of surgery and at 6 am on the day of surgery. An $18 \mathrm{G}$ cannula was inserted in all patents in the premedication room.

The patients were randomly divided into 2 groups, Group A (control) patients received general anaesthesia and surgical wound infiltration with $20 \mathrm{ml}$ of $0.25 \%$ bupivacaine at the end of surgery whereas Group B (block) patients received ultrasound guided ESP block with $10 \mathrm{ml}$ of $2 \%$ lignocaine with adrenaline and $20 \mathrm{ml}$ of $0.25 \%$ bupivacaine with $8 \mathrm{mg}$ dexamethasone before induction of general anaesthesia

Patients in Group A were taken to block room; pulse oximeter, ECG and NIBP monitors were connected and $\mathrm{SpO}_{2}$, basal heart rate, blood pressure (BP) was recorded. Spine was palpated and ultrasound scanning of back of thoracic area was done. Because of ethical reasons a sham block was not performed in these patients. Then they were shifted to operating room, monitors were reattached and general anaesthesia was given by a separate anaesthesiologist who was not part of the research team. All the patients were administered general anaesthesia with intravenous midazolam $1 \mathrm{mg}$, propofol $2 \mathrm{mg} / \mathrm{kg}$, and fentanyl $2 \mu \mathrm{gm} / \mathrm{kg}$ and after checking whether patient is ventilatable, muscle relaxant intravenous vecuronium $0.1 \mathrm{mg} / \mathrm{kg}$ was given. Patients were intubated with 7 size endotracheal tube and after confirming bilateral air entry, anaesthesia was maintained with $\mathrm{O}_{2}+\mathrm{N}_{2} \mathrm{O}$ and isoflurane 1-2\%. Intraoperative monitoring included ECG, NIBP, $\mathrm{SpO}_{2}$ and $\mathrm{ETCO}_{2}$. At the end of surgery, these patients received local wound infiltration with $20 \mathrm{ml}$ of $0.25 \%$ bupivacaine just before extubation. Thereafter muscle relaxant was reversed with intravenous neostigmine $0.5 \mathrm{mg} / \mathrm{kg}$ and glycopyrrolate $0.08 \mathrm{mg} / \mathrm{kg}$. The patients were extubated when reversal from muscle relaxant was adequate and shifted to PACU.

Group B patients were taken to a block room, monitors were attached and basal heart rate, ECG, $\mathrm{BP}, \mathrm{SpO}_{2}$ were recorded. Spine was palpated from $\mathrm{C} 7$ downwards in sitting position; T5 spinous process was identified and marked with 
a permanent skin marker. Many studies of ESP block have been done in sitting and lateral positions. But in our pilot study, we found that prone position was the most comfortable position to the patient and for the anaesthesiologist performing the block. So, in our patients ESP block was given in prone position. All patients were given block after giving intravenous fentanyl $25 \mu \mathrm{gm}$. Thereafter the ipsilateral side of thorax was cleaned with betadine and draped. The procedure involves placing a high frequency linear probe $8-12 \mathrm{~Hz}$ of Mindray diagnostic ultrasound system model Z6, parallel to the midline in a cephalocaudad direction at T5 level and as the probe is moved laterally, the tip of transverse process is seen as flat hyper echoic structure approximately $3 \mathrm{~cm}$ lateral to the spine.

On further moving laterally, ribs can be seen as rounded structure with pleura in between. The transverse process is brought back to view and the needle entered from the cephalad end of the probe. The three muscles from outwards were recognized as trapezius, rhomboids major and erector spinae.

After giving local analgesia with $2 \mathrm{ml} 2 \%$ lignocaine, a 23G hypodermic needle of length $3 \mathrm{~cm}$ was used to perform block. If this $23 \mathrm{G}$ hypodermic needle failed to reach the transverse process in any patient, we had planned to use a $23 \mathrm{G}$ spinal needle, but in all our patients this length of needle was adequate to hit the transverse process. After hitting the transverse process the needle was withdrawn slightly and 2-3 $\mathrm{ml}$ of $2 \%$ lignocaine with adrenaline was injected. Needle tip location was confirmed by seeing the spread of the drug as expansion of space below erector spinae muscle off the bony shadow of the transverse process.

Thereafter rest of $2 \%$ lignocaine with adrenaline and 20 $\mathrm{ml}$ of $0.25 \%$ bupivacaine with $8 \mathrm{mg}$ dexamethasone was injected into the space. After giving the block, patient was made supine and shifted to operating room where they were administered routine general anaesthesia similar to the other group.

Monitoring of heart rate, $\mathrm{BP}$ and $\mathrm{SpO}_{2}$ was done throughout. Intraoperative rise in mean arterial pressure $(20$ $\%$ above baseline) or an increase in heart rate $(20 \%$ above baseline) was treated with additional doses of intravenous fentanyl in both groups. Requirement of additional doses of analgesics and muscle relaxants during intraoperative period was noted.

In the postoperative ICU, the patients were assessed every 2 hours for 12 hours and thereafter every 6 hours till 48 hours by a resident anaesthesiologist, who was not aware of the patient's group assignment and was not present inside the operation theatre complex. If the patient had VAS of $\geq 5$ or complained of pain, that time was recorded and intravenous tramadol $50 \mathrm{mg}$ was given. If, pain was not relieved within an hour, intravenous paracetamol $1 \mathrm{gm}$ was given. The duration of analgesia was calculated based on the time of rescue analgesia.

The VAS score and requirement of analgesics in 24 hours and 48 hours period was noted. Patient satisfaction with postoperative analgesia was evaluated according to a satisfaction score (1 - very dissatisfied / 5 - extremely satisfied).

Incidence of failure of block, sparing of dermatomes, block related complications like nerve injury, vascular puncture, pneumothorax and local anaesthetic toxicity were noted.
The primary outcome of the study was the duration of analgesia calculated based on the time when the rescue analgesia was given.

The secondary outcome included patient satisfaction, additional requirement of intraoperative fentanyl and vecuronium, postoperative tramadol and paracetamol, quality of analgesia at rest and at arm movements

\section{Sample Size ${ }^{7}$}

Estimated based on the difference in proportion of subjects with postoperative pain in Group A (ESP block group) and Group B (control group) from the pilot study. Proportion of subjects with postoperative pain in Group A was $16.7 \%$ and in Group B was $100 \%$. Using these values in the below mentioned formula

$$
N=2(Z \alpha / 2+Z \beta)^{2} P(1-P) \div(p 1-p 2)^{2}
$$

Where,

$\mathrm{Z} \alpha / 2=\mathrm{Z} 0.05 / 2=\mathrm{Z} 0.025=2.58$ at type 1 error of $1 \%$

$\mathrm{Z} \beta=\mathrm{Z} 0.20=1.28=$ at $90 \%$ power

p $1-\mathrm{p} 2=$ Difference in proportion in the two different groups $=83.3 \%$

$\mathrm{P}=$ Pooled prevalence $=[$ Proportion in Group A $(\mathrm{p} 1)+$ Proportion in Group B (p 2)] $/ 2=[16.7+100] / 2=58.35$

$\mathrm{N}=2 \times(2.58+1.28){ }^{2} \times 58.35 \times 41.65 \div(83.3)^{2}=72420.3 /$ $6938.9=10.43 \approx 11$ in each group

Considering non response rate of $10 \%, 11+1.1=12.1 \approx 13$ patients was included in each group

\section{Statistical Analysis $8,9,10,11$}

Data was entered into Microsoft Excel data sheet and was analysed using SPSS 22 version software (IBM SPSS Statistics, Somers NY, USA). Categorical data was represented in the form of frequencies and proportions. Continuous data was represented as mean and standard deviation. Independent $t$ test or Mann Whitney U test was used as test of significance to identify the mean difference between two quantitative variables and qualitative variables respectively.

MS Excel and MS word was used to obtain graphs, $p$ value (Probability that the result is true) of $<0.05$ was considered as statistically significant after assuming all the rules of statistical tests.

\section{RESULTS}

A total of 26 consecutive patients were randomised and all patients in the study received their allocated intervention.

\begin{tabular}{|cccccc|}
\hline & Group A & \multicolumn{2}{c|}{ Group B } & p \\
& Mean & SD & Mean & SD & value \\
Age (years) & 59.69 & 14.86 & 60.92 & 13.07 & 0.824 \\
Duration of surgery (min) & 140.00 & 22.08 & 140.00 & 17.91 & 1.000 \\
\hline Table 1. Comparison of Age and Duration of Surgery between \\
\\
Two Groups \\
\hline \$ Independent t test
\end{tabular}

Mean age of subjects in Group A was $59.7 \pm 14.8$ years and in Group B was $60.9 \pm 13.1$ years. Mean duration of surgery in Group A was $140.00 \pm 22.08 \mathrm{~min}$ and in Group B was 140.00 
$\pm 17.91 \mathrm{~min}$. There was no significant difference in mean age and duration of surgery between two groups.

\section{Intraoperative Parameters}

\begin{tabular}{|c|c|c|c|c|c|}
\hline \multirow{2}{*}{ Dose } & \multicolumn{2}{|c|}{ Group A } & \multicolumn{2}{|c|}{ Group B } & \multirow{2}{*}{ p value ${ }^{\$}$} \\
\hline & Mean & SD & Mean & SD & \\
\hline Fentanyl ( $\mu \mathrm{g})$ & 36.67 & 11.69 & 20.00 & .00 & 0.104 \\
\hline Vecuronium ( $\mathrm{mg}$ ) & 2.17 & 1.03 & 1.00 & .00 & $0.005^{*}$ \\
\hline \multicolumn{6}{|c|}{$\begin{array}{c}\text { Table 2. Comparison of Dose of Fentanyl and Vecuronium Used } \\
\text { between Two Groups }\end{array}$} \\
\hline
\end{tabular}

Mean fentanyl dose used in Group A was $36.67 \pm 11.69 \mu \mathrm{g}$ and in Group B was $20.00 \pm 0.00 \mu \mathrm{g}$. The difference in mean fentanyl dose between two groups was not significant. Mean vecuronium dose used in Group A was $2.17 \pm 1.03 \mathrm{mg}$ and in Group B was $1.00 \pm 0.00 \mathrm{mg}$. There was significant difference in mean vecuronium dose between two groups.

\section{Post-operative Parameters}

(a) Tramadol and Paracetamol Dose at 24 Hours and 48 Hours

\begin{tabular}{|c|c|c|c|c|c|c|}
\hline & & \multicolumn{2}{|c|}{ Group A } & \multicolumn{2}{|c|}{ Group B } & \multirow{2}{*}{$\begin{array}{c}\text { p } \\
\text { value }\end{array}$} \\
\hline & & Mean & SD & Mean & SD & \\
\hline \multirow[b]{2}{*}{$\begin{array}{l}\text { Tramadol } \\
\text { dose }(\mathrm{mg})\end{array}$} & 24 hours & 111.54 & 21.93 & & . & - \\
\hline & $\begin{array}{l}48 \text { hours (including } \\
\text { dose in } 24 \text { hours) }\end{array}$ & 165.38 & 31.52 & 50.00 & .00 & $<0.001^{*}$ \\
\hline \multirow[b]{2}{*}{$\begin{array}{l}\text { Paracetamol } \\
\quad(\mathrm{gm})\end{array}$} & 24 hours & 2.00 & 0.00 & & . & - \\
\hline & $\begin{array}{l}48 \text { hours (including } \\
\text { dose in } 24 \text { hours) }\end{array}$ & 3.62 & 0.51 & 1.00 & .00 & $<0.001^{*}$ \\
\hline \multicolumn{7}{|c|}{$\begin{array}{c}\text { Table 3. Comparison of Tramadol and Paracetamol Dose at } 24 \text { Hours } \\
\text { and } 48 \text { Hours between Two Groups }\end{array}$} \\
\hline
\end{tabular}

In Group A, mean tramadol dose needed in 24 hours was $111.54 \mathrm{mg}$, in 48 hours was $165.38 \mathrm{mg}$. In Group B, mean tramadol dose needed in 24 hours was $0 \mathrm{mg}$, in 48 hours was $50 \mathrm{mg}$. There was significant difference in mean tramadol dose needed between two groups. Group B required lesser tramadol dose compared to Group A.

In Group A, mean paracetamol dose needed in 24 hours was $2 \mathrm{gm}$, in 48 hours was $3.62 \mathrm{gm}$. In the Group B, mean paracetamol dose needed in 24 hours was 0 gm, in 48 hours was $1 \mathrm{gm}$. There was significant difference in mean paracetamol dose needed between two groups. Group B required lesser paracetamol dose compared to Group A.

\section{(b) Median Pain Score at Rest}

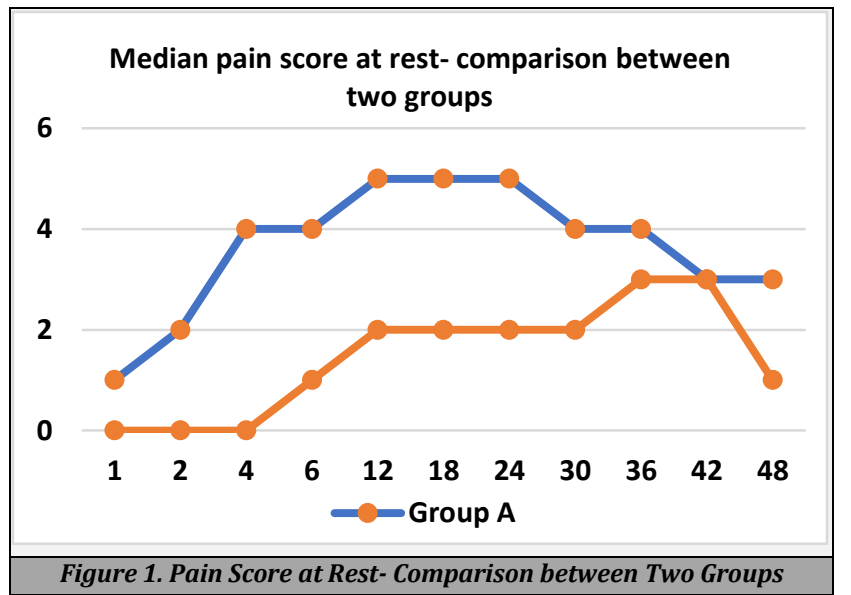

At rest, there was significant difference in median pain score from 1 hour to 48 hours between two groups except at 36 hours and 42 hours. Median pain score was high in Group A compared to Group B. Hence Group B had better pain reduction compared to Group A.

\section{(C) Median Pain Score at Arm Movement}

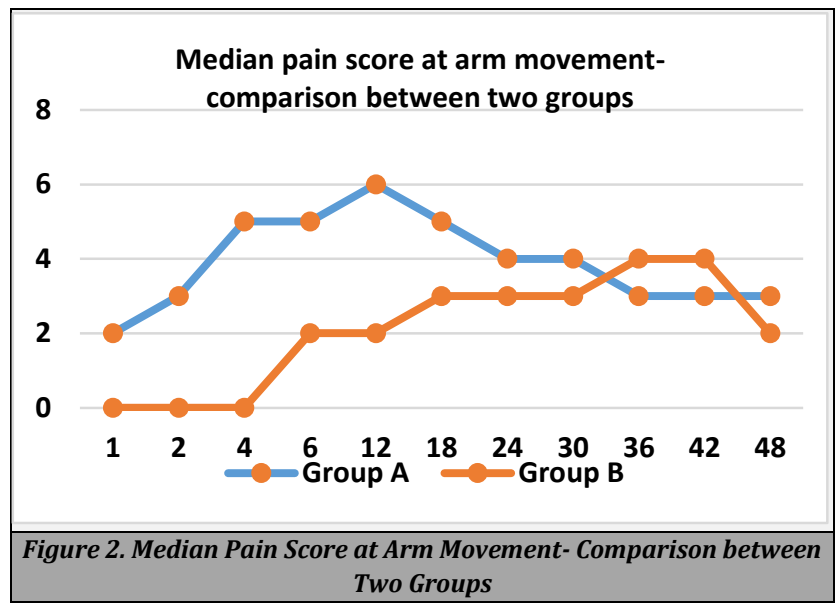

During arm movement, there was significant difference in median pain score from 1 hour to 36 hours between two groups. Median pain score was high in Group A compared to Group B. Hence Group B had better pain reduction compared to Group A. There was no significant difference between two groups at 42 hours and 48 hours. In Group B, VAS score was higher during arm movements than at rest

\section{(d) Satisfaction Score \& Postoperative Analgesia}

\begin{tabular}{|cccccccc|}
\hline & \multicolumn{3}{c}{ Group A } & \multicolumn{3}{c|}{ Group B } & p value \\
& Mean & SD & Median Mean & SD & Median & \\
Satisfaction score & 3.62 & 0.506 & 4 & 4.77 & 0.439 & 5 & $<0.001^{*} \#$ \\
$\begin{array}{c}\text { Post-operative } \\
\text { analgesia (min) }\end{array}$ & 274.23 & 33.345 & 280 & 2594.62 & 216.742 & 2760 & $<0.001^{*} \$$ \\
\hline Table 4. Satisfaction Score \& Postoperative Analgesia-Comparison \\
between Two Groups \\
\hline \#Mann Whitney U test, \$ Independent t test \\
\hline
\end{tabular}

In Group A, median satisfaction score was 4 and in Group $B$ was 5 . The difference in median satisfaction score between two groups was significant.

Mean duration of post-operative analgesia in Group A was $274.2 \pm 33.3 \mathrm{~min}$ and in Group B group was $2594.62 \pm 216.742$ min. There was significant difference in mean post-operative analgesia between two groups.

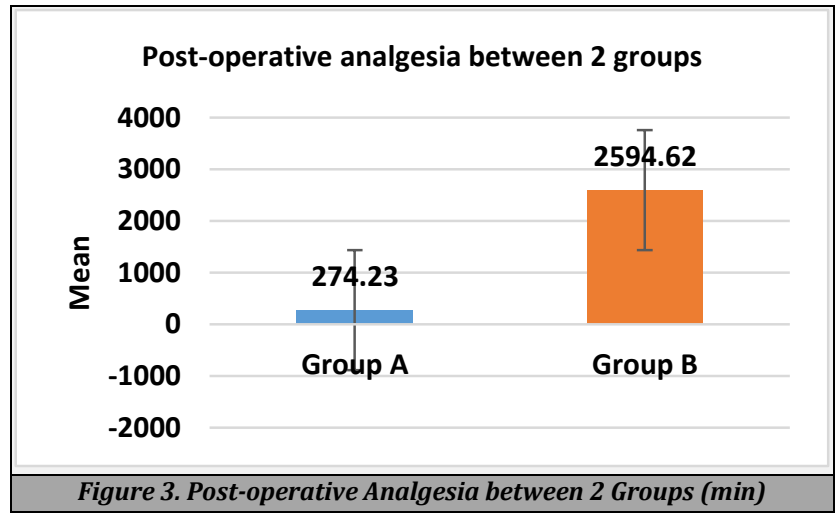




\section{DISCUSSION}

Increased incidence of breast cancer surgeries mandates better analgesic techniques. Currently paravertebral block is the gold standard of pain management. Unfortunately, contraindications like coagulopathies, anticoagulant therapy and difficulty in performing the block may exclude many patients from this treatment. ESP block was first described in 2016 by Forero $\mathrm{M}$ et al. as a novel regional anaesthetic technique for thoracic neuropathic pain and for acute postoperative pain. ${ }^{3}$ It is a paraspinal fascial plane block that involves injection of local anaesthetic deep to erector spinae muscles and superficial to the tips of the thoracic transverse process. Erector spinae muscle is formed of spinalis muscle, longissimus muscle, and Iliocostalis muscle. They lie on each side of the vertebral column and their fibres run vertically along the whole length of spine. Each upper thoracic spinal nerve exits from intervertebral foramen and splits into dorsal and ventral rami. The dorsal ramus traverses posteriorly through the costo transverse foramen and ascends into the erector spinae muscle, divides into lateral and medial branches, medial branch ascends superficially and continue as posterior cutaneous branch. The ventral ramus travels laterally as intercostal nerve. On injection of drug in the erector spinae plane, the mechanism of analgesic action is believed to result from diffusion of local anaesthetic anteriorly via costo transverse foramina into the vicinity of origin of dorsal and ventral rami of thoracic spinal nerve, thus blocking both of them. It also blocks rami communicantes which contain fibres connecting sympathetic ganglion with spinal nerves leading to somatic and visceral analgesia. The drug also spreads in a cephalocaudad fashion and as erector spinae muscle extends along the whole length of thoracolumbar spine, it blocks multiple dermatomes. Using an ultrasound machine, the tip of transverse process is seen as flat hyper echoic structure approximately $3 \mathrm{~cm}$ lateral to the spine. Simple identification of ultrasound landmark makes procedure comparatively easier than thoracic epidural or thoracic paravertebral block. The site of injection is distant from pleura, major blood vessel and spinal cord, hence performing the block has fewer contraindications. Potential complications include bleeding, local anaesthetic toxicity, and pneumothorax. Proper identification of transverse process prevents any chance of pneumothorax.

Cadaveric studies have showed that T5 level block is sufficient to produce multidermatomal sensory block ranging from T1 to L3 in ipsilateral side. This block serves the purpose of a paravertebral block without risk of pleural injury. ESP block for MRM has been performed at T3 level by Wensheng He et al. ${ }^{12}$ at T4 level by Nair AS et al. ${ }^{13}$ and at T5 level by Swati Singh et al. ${ }^{14}$ In our study, we have given unilateral ESP block at T5 level.

26 patients undergoing MRM were assigned into two groups - general anaesthesia with local anaesthetic infiltration towards the end of surgery was given to one group and ESP block followed by general anaesthesia was given to the other group. . Both groups were comparable in mean age and duration of surgery. All of our patient belonged to ASA I or II. The results were significant prolongation of analgesia and reduced VAS score in the post-operative period up to 48 hours.
In our study, we found out that the time of first analgesic requirement was prolonged in ESP block group 2594.12 \pm 216.742 minutes ( $43.23 \pm 3.6$ hours) vs. $274.2 \pm 33.3$ minutes (4.57 \pm 0.55 hours) in local infiltration group. This result is consistent with the study done by Aman Malawat et al. ${ }^{15}$ who used $25 \mathrm{ml}$ of $0.5 \%$ bupivacaine and $8 \mathrm{mg}$ dexamethasone for ESP block group and reported long lasting analgesia of 41.73 hours. Moustafa A Moustafa et al. ${ }^{16}$ reported the time to first analgesic requirement as $11.04 \pm 1.9$ hours. The difference in time duration between our study and that of Mustafa et al. could be that in their study they used only $20 \mathrm{ml}$ of $0.25 \%$ bupivacaine whereas in our study we have used $10 \mathrm{ml}$ of $2 \%$ lignocaine with adrenaline and $20 \mathrm{ml}$ of $0.25 \%$ bupivacaine and $8 \mathrm{mg}$ dexamethasone $(30 \mathrm{ml})$. The increased volume of drug and addition of adrenaline and dexamethasone could also have resulted in prolongation of block. Numerous studies have been done with addition of dexamethasone to brachial plexus block resulting in prolonged duration of block.17,18,19

Gürkan Y et al. ${ }^{20}$ noted a $65 \%$ decrease in total morphine consumption at 24 hours in patients who received ESP block for breast cancer surgery which was statistically significant compared to control group. Nair AS et al. ${ }^{13}$ in their case series of 5 patients also reported opioid sparing effect of ESP block. These results were similar to our conclusions as we observed reduced requirement of tramadol and paracetamol in the postoperative period in patients who were administered block. Swati Singh et al. ${ }^{14}$ conducted a study on 40 patients to evaluate the post-operative analgesic efficacy of ESP block for 24 hours and noted that only $3 / 20$ patients required supplemental morphine. In our study none of the patients who received ESP block required rescue analgesia in first 24 hours. Similar to our study, Wensheng He et al. ${ }^{12}$ and Aman Malawat et al. ${ }^{15}$ also found that VAS score at rest and in motion in ESP block group was significantly lower than those in control group.

In our study, patients in ESP block group had better satisfaction score. Block related complications namely nerve injury, vascular puncture, pneumothorax and local anaesthetic toxicity was not observed. However, since higher VAS scores were observed during arm movements than at rest, a level above $\mathrm{T} 5$ would be more useful while performing this block for postoperative analgesia in mastectomies.

Our study had some limitations. Firstly, we did not investigate the spread of local anaesthetic by using ultrasound scanning. Secondly, even though both group of patients were taken to block room preoperatively and ultrasound scan of back was done, inability to perform a sham block due to ethical reasons prevented the complete blinding of the two groups. However, we did our level best by taking them to block room and performing an ultrasound scan on them. The anaesthesiologist doing the procedure was not blinded, however those who collected data were blinded to group distribution.

\section{CONCLUSIONS}

ESP block in MRM significantly prolongs post-operative analgesia with decreased VAS score at rest and in motion. The transverse process is a convenient sonographic landmark, easy to identify and there are no structures at risk of needle 
injury in the vicinity, ensuring the safety of block. This block being easy to perform and well tolerated by the patient has the potential to become a popular block for prolonging postoperative analgesia after MRM.

\section{REFERENCES}

[1] Malvia S, Bagadi SA, Dubey US, et al. Epidemiology of breast cancer in Indian women. Asia Pac J Clin Oncol 2017;13(4):289-95.

[2] Tam KW, Chen SY, Huang TW, et al. Effect of wound infiltration with ropivacaine or bupivacaine analgesia in breast cancer surgery: A meta-analysis of randomized controlled trials. Int J Surg 2015;22:79-85.

[3] Forero M, Adhikary SD, Lopez H, et al. The erector spinae plane block: a novel analgesic technique in thoracic neuropathic pain. Reg Anesth Pain Med 2016;41(5):6217.

[4] Chin KJ, Malhas L, Perlas A. The erector spinae plane block provides visceral abdominal analgesia in bariatric surgery: a report of 3 cases. Reg Anesth Pain Med 2017;42(3):372-6.

[5] Adhikary SD, Pruett A, Forero M, et al. Erector spinae plane block as an alternative to epidural analgesia for postoperative analgesia following video-assisted thoracoscopic surgery: a case study and a literature review on the spread of local anaesthetic in the erector spinae plane. Indian J Anaesth 2018;62(1):75-8.

[6] Altıparmak B, Toker MK, Uvsal AI, et al. Ultrasoundguided erector spinae plane block versus oblique subcostal transversus abdominis plane block for postoperative analgesia of adult patients undergoing laparoscopic cholecystectomy: randomized, controlled trial. J Clin Anesth 2019;57:31-6.

[7] Charan J, Biswas T. How to calculate sample size for different study designs in medical research? Indian J Psychol Med 2013;35(2):121-6.

[8] Gaddis ML, Gaddis GM. Introduction to biostatistics: part 4, statistical inference techniques in hypothesis testing. Ann Emerg Med 1990;19(7):820-5.

[9] Patra P. Sample size in clinical research, the number we need. Int J Med Sci Public Health 2012;1(1):5-9.
[10] Sunder Rao PSS, Richard J. An introduction to biostatistics: a manual for students in health sciences. $4^{\text {th }}$ edn. New Delhi: Prentice hall of India 2006:86-160.

[11] Elenbaas RM, Elenbaas JK, Cuddy PG. Evaluating the medical literature, part II: statistical analysis. Ann Emerg Med 1983;12(10):610-20.

[12] He W, Wu Z, Zu L, et al. Application of erector spinae plane block guided by ultrasound for postoperative analgesia in breast cancer surgery: a randomized controlled trial. Cancer Commun 2020;40(2-3):122-5.

[13] Nair AS, Seelam S, Naik V, et al. Opioid-free mastectomy in combination with ultrasound-guided erector spinae block: a series of five cases. Indian J Anaesth 2018;62(8):632-4.

[14] Singh S, Kumar G, Akhileshwar. Ultrasound-guided erector spinae plane block for postoperative analgesia in modified radical mastectomy: a randomised control study. Indian J Anaesth 2019;63(3):200-4.

[15] Malawat A, Verma K, Jethava D, et al. Erector spinae plane block for complete surgical anaesthesia and postoperative analgesia for breast surgeries: a prospective feasibility study of 30 cases. Indian J Anaesth 2020;64(2):118-24.

[16] Moustafa MA, Alabd AS, Ahmed AMM, et al. Erector spinae versus paravertebral plane blocks in modified radical mastectomy: randomised comparative study of the technique success rate among novice anaesthesiologists. Indian J Anaesth 2020;64(1):49-54.

[17] Dar FA, Najar MR, Jan N. Effect of addition of dexamethasone to ropivacaine in supraclavicular brachial plexus block. Indian J Pain 2013;27(3):165-9.

[18] Biradar PA, Kaimar P, Gopalakrishna K. Effect of dexamethasone added to lidocaine in supraclavicular brachial plexus block: a prospective, randomised, doubleblind study. Indian J Anaesth 2013;57(2):180-4.

[19] Choi S, Rodseth R, McCartney CJL. Effects of dexamethasone as a local anaesthetic adjuvant for brachial plexus block: a systematic review and metaanalysis of randomized trials. $\mathrm{Br} \mathrm{J}$ Anaesth 2014;112(3):427-39.

[20] Gürkan Y, Aksu C, Kuş A, et al. Ultrasound guided erector spinae plane block reduces postoperative opioid consumption following breast surgery: a randomized controlled study. J Clin Anesth 2018;50:65-8. 